\title{
XLIX. On the preparation and use of copal varnish as a vehicle preferable to oil for the purposes of the painter
}

\author{
Mr. Cornelius Varley
}

To cite this article: Mr. Cornelius Varley (1818) XLIX. On the preparation and use of copal varnish as a vehicle preferable to oil for the purposes of the painter, Philosophical Magazine Series 1, 51:240, 289-291, DOI: 10.1080/14786441808637551

To link to this article: http://dx.doi.org/10.1080/14786441808637551

电 Published online: 27 Jul 2009.

Submit your article to this journal $\pi$

Џll Article views: 2

Q View related articles $\sqsubset$ 
XLIX. On the Preparation and Use of Copal Vurnish as a Fehicle preferable to Oit for the Purposes of the Painter. By Mr. Cornelius Varley.

\section{To Mr. Tillock.}

$S_{1 R},-I$ BEG, through the medium of your valuable Magazine, to lay before artists the method of preparing pure copal varnish in spirits of turpentine *, without heat. It is quite transparent, colourless, durable, protects the colours, and does not change in the least. This is the purest material I have yet found, and is the only vehicle I use to paint with.

Take the cleanest and whitest lumps of copal; beat them small, and pick out all the impurities. Pound them to a fine mass in a glass or Wedgwood's mortar; then pour in coloun less spirits of turpentine to about one-third higher than the copal, and work up the whole quite fine; in hall an hour work it up again till fine (if left too long, it will get so tough as not to be rubbed up again) ; and in an hour work it up again, and once or twice nore in the course of the day. The next morning it may be poured off into a bottle for use; but as it is thicker or thinner according to the quantity of turpentine and the heat of the weather, it should be tried as follows, before bottling it up: Dip a paletteknife in, and dry it by the fire as quick as you can without burning it; and if, when cold, it is found to have left on the knife a fair coat of varnish, it is strong enough : otherwise, work it up again, and let it stand some time longer. After taking off this first supply, pour on a fresh quantity of turpentine, and rub it up several times during two or three days;-try it by the paletteknife as before; and when strong enough, pour the liquid off into the same bottle with the first. A third quantity of spirits might be added, which would make the remaining copal appear as dry as crumb of bread; but a much longer time than before would be recyuired for the solution.

To paint with this varnish, use powder colours ground guite fine; or else grind them in spirits of turpentine, and add as much of the varnish as will bind them well. Keep them in bottles, and mix your tints in saucers for use; and as they thicken by

ing fires in ships; but as the idea had alrealy been anticipatcd in our xxist rol. p. 97 , to which our reader's can turn, it was unnecessary to insert them here. He also suggests that ships might be rendered more buoyant by making them air-tight, and forcing in air by means of an air-pump, which would elevate them to a higher level in the water, and consequently might sometimes save them when they have got upon a bank.

* The common spirits of turpentine seems to dissolve copal best; but when that cannot be had colourless, I use the rexitied spirits.

Vol.51. No. 240. Apill 1818. 
drying, thin them with pure turpentine. I purposely make the varrish so thin as not to shine when the paint is dry; hut if it work too drv, moisten with a little more varnish till right; and if it becone too thick so as to work gummy, add powder colour and turpentine till it is brought to a proper consistence. I kecp these saucers of colour clean in a small chest of drawers, by which I have a great many in a little compass; and the colours are continualiy set for use, as they only require moistening in the morning with turpentine. I do not however always wait to soften them in this way, but put fresh colour upon the old, out of the bottles.

The colours work freest, and dry quickest, when they do not shine, and will remain exactly as you put them on; but if there is too much varnish, and the canvass is painted frequently over in the same day, the sharp touches will spread a little; a fault which must be avoided by using no more varnish than just enough to shine, and $b y$ drying the part more perfectly before painting on it. In cold weat her, the drying may be effected by the fire, or by holding a hot iron before the canvass; in cold weather, you must not expose the painting to a hot fire directly afterwards, as it would melt and run, but let it dry two or three hours, and then bring it to the fire to finish. 'The picture may be varnished with the same varnish made thicker (if you wish to be sure of the purity of the materials), and when varnished, dry it as soon as convenient by gradually approaching the fire, avoiding a heat that would melt the copal. After this perfect drying, no dirt or stnoke will crer stick to the picture; but it may be dusted or washed quite clcan with pure water, and will never change.

The next varnish I generally employ is made in the following manner: Take the sediment of the first varnish or fresh copal beat small; cover it to about twice its height with turpentine in which camphor is dissolved, (an ounce to a quart,) cork it up, shake it well, and put it by for a year, at the end of which it will be dissolved. The first portion that is dissolved thickens the turpentine, and enables it to dissolve the remainder; but if the turpentine is too much diluted, the remainder will never dissolve, so that it is easier to make thick camphor varnish than thin. It Inust not, however, be made too thick at first; but when that which is put by is thick enough, pour it off for use, and add fresh camphor and turpentine to the remainder, and put it by again till dissolved, which it will be in the course of time. If you want that which is put by before it is quite dissolved, it may then be put in a sauccpan of cold water with the cork loosened, and made to boil for an hour, stirring it well up two or three times towards the cnd, and that will finish the dissolution.

I paint suall pictures on the finest mill-boards glued to a deal frame, 
frame, and I take care to prevent the larger pictures from swagging, by not allowing the canvass to be tightened afterwards, but custing the picture off the frame on which it was painted, and then pasting it to very tight canvass protected from swagging by pannels. This mode of preventing cracking is of real advantage; for all pictures will imbibe the smoke of London, and become tinged in proportion to the softness which is had recourse to for this purpose.

A third varnish is quickly made by oil of spike-lavender, which is very good for drawings or prints, but will not do for pictures, as it will dissolve the paint underneath and run down while drying. I remain, sir, Your most obedient servant, 42 Newman-street, May 17, $1816 . \quad$ Cornelius Varley.

L. On the Saltness of the Allantic Ocean. By M. GAYLussac*.

M. Lamarche, a distinguished officer of marine, collected the water of the sea at different latitudes during a voyage from Rio Janeiro to France in the year 1816 , and on his return to Paris he brought it to me in order to submit it to some experiments, The water had been taken from the surface of the sea, and preserved in glass bottles closed with stop corks, and for the most part tarred,

I at first proposed to myself to examine the nature and the proportions of the salme substances which they contained; but I found myseif relieved from the necessity of such examination, by the analysis of the water of the Frith of Forth by Mr. John Murray, who appears to have made it with much care, and from which it results that this water contains in 100 parts

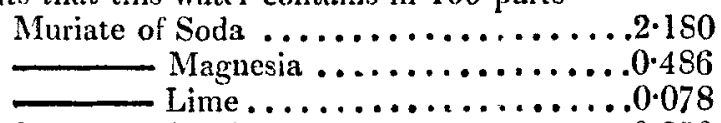

Sulphate of Soda.................. $0 \cdot 350$

I contented myself with determining the specific weight and quantity of the saline matters of each specimen. The experiments were made in my laboratory by $M$. Despretz with all possible care. The specific weight was taken, by weighing successively the same vessel, first empty, then full of distilled water, and afterwards full of sea-water at the constant temperature 'of $8^{\circ}$.

The total quantity of saline matters may be determined by analysis, in the manner adopted by Mr. Murray; but it is more simple and more exact to determine it by evaporation. This operation is done very conveniently by putting the water in a phial,

* Frow the Annales de Ch:mie for December 1817. 